\title{
Educação Lúdica no Cenário do Ensino Superior
}

\section{Ludic education in the scenario of higher education}

Luciana Hoppe é publicitária (PUC-RS), pós-graduada em Marketing (ESPM), mestre em Administração (UFRGS), coordenadora dos CSTs Marketing e Eventos no Unilasalle Canoas. Docente na FTEC NH e Unilasalle Canoas. Consultora na SIM! Planejamento e Pesquisa Ltda.

Contato: luciana@simplanejamentopesquisa.com.br

Adriane Maria Santos Kroeff é fonoaudióloga (IPA-RS), doutora em Educação pela Universidade de Colônia/Alemanha, docente no Centro Universitário Metodista - IPA, Educinter e Capacitarh. Consultora na AKNetzwork e na AKToys Brinquedos e Jogos Educativos.

Contato: adriane.kroeff@metodistadosul.edu.br

\section{Resumo}

Este artigo propõe-se a provocar uma reflexão a respeito da educação lúdica voltada a adultos - em especial no Ensino Superior -, e suas implicações no desenvolvimento de competências. Entre as suas principais contribuições destaca-se a percepção de que o lúdico pode trazer importantes benefícios à educação, além de promover um consequente desenvolvimento humano a partir de um cenário prazeroso e divertido. Leva em conta ainda a questão da necessidade de uma nova forma de perceber o processo de ensinar e aprender, enxergando a pessoa como agente transformador de sua realidade e do cenário no qual se insere. Salienta que muito deve ser ainda discutido a respeito desse tema, que apresenta grande potencial transformador da sociedade atual.

Palavras-chave: Educação; Ludicidade; Competências; Habilidades; Adultos. 


\begin{abstract}
This paper aims to reflect about the ludic education for adults - especially in higher education -, and its implications in the development of skills. Among the major contributions there is the perception that the play can bring important benefits to education and also provides the consequent human development, from a pleasurable and fun setting. It aims also the question of the need for a new way to understand the process of teaching and learning, understanding the person as an agent of his reality and context. It concludes that further discussion must be carried out about this topic, which has great potential to transform the present society. Keywords: Education; Ludic; Competences; Skills; Adults.
\end{abstract}

\title{
Introdução
}

Lecionar para adultos, especialmente no ensino superior, apresenta muitos desafios. A fim de ultrapassar tais desafios, uma das estratégias que se mostra bastante positiva, depois de superar a barreira inicial, é o uso de jogos e dinâmicas em sala de aula. Com foco no desenvolvimento de competências, tal abordagem mostra-se interessante para educação de adultos. Essas práticas despertam a atenção dos discentes, bem como sua motivação e engajamento nas atividades de aula. Com isso, a ancoragem dos novos saberes acaba sendo mais significativa.

Evidentemente, é importante entender o conceito de jogo, a fim de contextualizá-lo dentro das práticas educativas indicadas para adultos. Nesse sentido, Von Neumann e Morgenstern (1944) esclarece que um jogo se refere a situações dadas entre dois ou mais indivíduos e que ocorrem dentro de um conjunto específico de regras. Na mesma direção, Salen e Zimmerman (2012) assinalam que os jogos são sistemas nos quais jogadores desenvolvem um conflito guiado por regras deliberadas que conduzirão a um resultado quantificável.

Legitimando essa ideia, pode-se levar em conta igualmente a definição dada por Huizinga (1993, p. 33), ao afirmar que o jogo é

Uma atividade voluntária exercida dentro de certos e determinados limites de tempo e espaço, segundo regras livremente consentidas, mas absolutamente obrigatórias, dotado 
de um fim em si mesmo, acompanhado de um sentimento de tensão e alegria e de uma consciência de ser diferente da vida cotidiana.

A relevância educativa dos jogos advém dos colégios jesuítas, pioneiros no uso de tal ferramenta na educação. Esse uso alterou aos poucos a visão sobre os jogos, anteriormente muito aplicada ao universo infantil, a fim de que o valor na formação das pessoas fosse percebido (ALMEIDA, 2003). Com o passar do tempo, tal percepção do lúdico ultrapassou o âmbito da infância e ampliou-se para as mais variadas faixas etárias.

Também é preciso levar em conta que Luckesi (2005) apresenta uma relação do ensinar e do aprender ludicamente com a formação de uma individualidade saudável, ao salientar que:

A atividade lúdica propicia um estado de consciência livre dos controles do ego, por isso mesmo criativo. [...] Por isso, uma educação centrada em atividades lúdicas tem a possibilidade, de um lado, de construir um Eu (não um ego) saudável em cada um de nós, ou, por outro lado, vagarosamente, auxiliar a transformação do nosso ego constritivo num Eu saudável. Educar crianças ludicamente é estar auxiliando-as a viver bem o presente e preparar-se para o futuro. Educar ludicamente adolescentes e adultos significa estar criando condições de restauração do passado, vivendo bem o presente e construindo o futuro (LUCKESI, 2005, p. 43).

Nesse contexto, considera-se que a ludicidade na educação é maior do que o uso de simples brincadeiras para passar o tempo. Além disso, o lúdico é uma forma de ação inerente ao ser humano - independentemente de sua idade. Assim sendo, considera-se que a educação lúdica é

\section{[... uma forma transacional em direção a algum conhecimento, que se redefine na elaboração constante do pensamento individual e em permuta- ções com o pensamento coletivo (ALMEIDA, 2003, p. 13).}

Isso ocorre porque o lúdico pressupõe uma entrega total da pessoa, integrando corpo e mente como mostra Luckesi (2005), ao afirmar que a atividade lúdica é una, indivisível, sendo que por meio desse tipo de atividade se objetiva um estado de consciência que liga o cognitivo à ação.

Complementando essa ideia, Almeida (2003, p. 14) afirma que "educar ludicamente tem um significado muito profundo e está presente em todos os segmentos da vida". 0 autor menciona, 
da mesma forma, que no brincar e se divertir a pessoa está igualmente se desenvolvendo e, ao mesmo tempo, operando múltiplas funções tanto cognitivas como sociais. Isso ocorre, segundo o autor, porque existe a integração e mobilização de várias relações funcionais relativas ao prazer de interiorizar o conhecimento e a expressão de felicidade revelada de integração com outros indivíduos. Assim sendo, a contribuição da ludicidade no desenvolvimento das pessoas se dá porque quando elas agem ludicamente acabam por viver uma experiência plena.

0 educador tem diante de si, então, um instrumento pedagógico importante. Cabe a ele direcioná-lo aos seus objetivos, desenvolvendo as competências e habilidades necessárias em seus alunos.

\section{Novos paradigmas no ensino superior}

É importante considerar, nesse sentido, o contexto do Ensino Superior, em especial no Brasil. Apoiando-se nas reformas realizadas na década de 1990, passou-se a buscar novos processos de ensino-aprendizagem. Tais formas, balizadas na concepção de que esse nível de escolaridade, segundo Silva (2014, p. 415), foca-se na "formação de profissionais que desenvolvam, estimulem e ampliem as áreas de ciências, tecnologias e cultura" perpassam pela percepção que além de saber, é preciso que esse profissional saiba fazer e saiba ser. Assim sendo, evidencia-se a necessidade de que sejam trabalhadas questões atinentes aos seus conhecimentos, habilidades e atitudes, o que demanda uma visão do Ensino Superior mais abrangente, demandando novas formas de ensinar e aprender. Deve-se levar em conta, então, a afirmação de Quadros e Mortimer (2014, p. 260) de que "no Ensino Superior, o estudante - assim como nos demais níveis da educação formal - é um sujeito em formação. 0 desenvolvimento individual desses sujeitos passa, portanto, pela atividade social coletiva".

Ghelli (2004) ressalta que a aprendizagem do aluno universitário ocorre quando há efetivamente mudanças no seu comportamento. Ele tem a sensação de que construiu, descobriu e acrescentou algo na sua forma de pensar e ver determinada situação. Diz ainda que o estudante busca significados, reconstrói o conhecimento visto em aula e as informações que foram transmitidas. E que quando as atividades são bem conduzidas permite que o professor perceba o discente como sujeito de seu processo de aprender, pois coloca a ênfase na atividade do estudante. 


\section{O planejamento do uso de jogos em sala de aula}

Os jogos já vêm, há muito tempo, sendo utilizados na educação infantil que, por meio do universo lúdico, experimenta novas situações, com a segurança que um jogo permite. Com adultos - como no caso da educação superior -, essa realidade também se aplica. Com dinâmicas, é possível desinibir, gerar um ambiente mais leve e propício para o conhecimento, melhorar relacionamentos e, principalmente, gerar um aprendizado com significado - o que é mais eficiente e durador.

E aí se encontra o diferencial da Educação Lúdica. Por meio do lúdico é possível que um indivíduo vivencie várias situações em um cenário diferente do da vida real. Porém, essas experiências, quando significadas, geram um arcabouço de memória que é acessada em outras situações concretas, pois geraram aprendizado.

Diante desse cenário, é claro que o planejamento da atividade, sua vivência e o domínio do professor a respeito do conteúdo trabalhado são fundamentais para o sucesso da aplicação de jogos e dinâmicas em sala de aula. Esse domínio garantirá a segurança necessária ao discente, uma vez que o aluno precisa sentir-se seguro e, assim, disponível para ingressar no mundo da ludicidade e a fim de gerar ancoragem e significação das suas aprendizagens.

Além disso, a geração de estratégias e, consequentemente, táticas e recursos operacionais é imperativa a fim de mobilizar a emoção e a razão dos agentes do processo de ensino e aprendizagem (RELVAS, 2009). Assim, é relevante perceber a existência de uma interação entre aquele que aprende e aquele que ensina.

Nesse processo ocorre troca mútua de conhecimento e experiências entre tais agentes, como aponta Luckesi (2005, p. 37):

\footnotetext{
A educação [...] é uma mediação bastante adequada para o cuidado do ser humano saudável, caso seja conduzida com adequação. Por si, ela está voltada para o futuro e, como tal, pode e deve servir de mediação para a construção de uma vida mais pulsante e saudável e, por isso mesmo, menos cronificada e, consequentemente, menos neurótica, no sentido reicheano.
}

Além da preparação do professor com foco na ludicidade, o planejamento da tarefa em si é extremamente importante. Nesse sentido, Militão e Militão (2000, p. 27) alerta que 


\begin{abstract}
Alguns sentidos devem ser considerados na preparação de um jogo: habilidade e idade dos participantes, ambiente de realização, riscos, segurança, material utilizado e duração. Ou seja, é preciso adequar o método, conteúdo do jogo, mensurar o nível de riscos, o que se vai utilizar e duração. São precauções que o facilitador deve tomar para não prejudicar os resultados e conclusões. Com isso, os participantes precisam estar inteiros, literalmente, envolvidos até o final.
\end{abstract}

Cabe ressaltar que os adultos, de forma diferente do que as crianças, demoram um pouco mais para entrar no universo da brincadeira, por isso a escolha das práticas deve ser feita com muito cuidado, sempre levando em conta os objetivos educacionais que se pretende atingir, bem como as habilidades e competências que se buscam desenvolver. Cuidado especial em, obviamente, não infantilizar o jogo, o que torna a aceitação dessas práticas mais efetiva.

Portanto, ao iniciar suas atividades de forma lúdica, o educador precisa mapear as características de seu grupo de alunos, identificando habilidades, traços de personalidade, aptidões, competências. Com base nisso, poderá identificar gaps entre os atributos desejados e os existentes.

Porém, para tanto, é necessário compreender alguns conceitos - distintos e complementares. Sebastião (2014) define competências como um conjunto de conhecimentos que habilita uma pessoa a confrontar e resolver situações ou problemas vivenciados. Já as habilidades são oriundas dos esforços de pôr em prática as competências já adquiridas. Dessa forma, para o autor, ambas dependem da ação dos indivíduos, podendo ser desenvolvidas - a pessoa deve saber, saber fazer, saber conviver e saber ser.

O uso de jogos tem, especificamente, a potencialidade de colaborar de forma concreta para o desenvolvimento de competências, capacidades, conhecimentos, atitudes e habilidades. Com o objetivo de ilustrar tal potencialidade, Batllori (2009) aponta uma lista de sentidos (tabela 1) que podem ser desenvolvidos em atividades lúdicas: 
- Favorecer a mobilidade

- Estimular a comunicação

- Ajudar a desenvolver a imaginação

- Facilitar a aquisição de novos conhecimentos

- Fomentar a diversão individual e em grupo

- Facilitar a observação de novos procedimentos

- Desenvolver a lógica e o sentido comum

- Proporcionar experiências

- Ajudar a explorar potencialidades e limitações

- Estimular a aceitação de hierarquias e o trabalho em equipe

- Incentivar a confiança e a comunicação

- Desenvolver habilidades manuais

- Estabelecer e revisar valores

- Agilizar a astúcia e o talento

- Ajudar na abordagem de temas transversais e conteúdos

- Agilizar o raciocínio verbal, numérico, visual e abstrato

- Incentivar o respeito às demais pessoas e culturas

- Aprender a resolver problemas ou dificuldades e procurar alternativas

- Estimular a aceitação às normas

Tabela 1 - Capacidades, competências e habilidades desenvolvidas com jogos

Fonte: adaptado de Batllori (2009, p.15) 
Depois de feito o diagnóstico do perfil dos alunos, ao planejar as suas atividades com base na ludicidade, o docente, precisa estar ciente dos objetivos que quer abranger. Isso o auxiliará na escolha das ferramentas a serem usadas em sua aula e que estas sejam compatíveis com as características de seus alunos e o aprendizado almejado. Assim, deve-se considerar que a conclusão é a geração de significado, importante no processo de aprendizagem, como aponta Militão e Militão (2000, p. 27):

Toda a atividade de grupo deve ter um ou mais objetivos: o que significa, quais as simbologias ou metáforas, qual a conexão com o real, as emoções e sentimentos gerados, etc. Esta é a fase que NÃO DEVE ser revelada previamente. Deve-se esperar a conclusão do próprio grupo.

De fato, a escolha das ferramentas deve sempre se originar dos objetivos e nunca o contrário, pois deve ser feita com foco nas características dos discentes, entendendo que um jogo dificilmente será jogado da mesma forma por diferentes pessoas. Nesse contexto, convém considerar que o docente poderá adaptar ferramentas já existentes à realidade de sua turma e de seus objetivos - mudando ou inventando regras.

A etapa seguinte no planejamento é a realização de um checklist dos materiais que serão utilizados nas atividades - recursos para desenhar, escrever, tabuleiros, peças, entre outros, que usados de maneira singular, deixam o jogo interessante. Convém apontar que existem atividades lúdicas que podem ser executadas sem materiais de apoio, que são úteis quando um docente precisa intervir rapidamente, pois seu tempo de preparo é mais ágil.

Outro aspecto significativo no planejamento de ações lúdicas é a capacitação do docente em tais atividades. 0 educador precisa ter jogado o jogo para assumir propriedade em sua realização. Da mesma forma, a prática é relevante para entender a dinâmica do grupo ao jogar. Por exemplo, em algumas ocasiões pode ser necessário adaptar as atividades e regras, dependendo de quantas pessoas estão participando no grupo, pois a grande parte dos jogos "prontos" tem como alvo um número diminuto de pessoas.

É evidente, então, que no cenário da educação lúdica é necessária a preparação do docente, por meio de um verdadeiro conhecimento sobre os processos e fundamentos dessa forma de aprender e ensinar. Assim, terá condições para compartilhar o conhecimento por meio da ludicidade (ALMEIDA, 2003). Isso ocorre porque a educação lúdica tem como fundamento o entendimento 
de que as pessoas são seres em movimento, em constante construção.

De forma diferente da pedagogia tradicional, tal modelo de educação apregoa o constante desenvolvimento do ser humano, por interações sociais e ambientais, como aponta Luckesi (2005, p. 42):

\footnotetext{
Uma prática educativa lúdica só pode assentar-se [...] sobre um entendimento de que o ser humano, através de sua atividade e consequentemente compreensão da mesma, constrói-se a cada momento, na perspectiva de tornar-se mais senhor de si mesmo, de forma flexível e saudável.
}

Diante disso, o processo do planejamento de jogos para o desenvolvimento de competências em adultos é ilustrado na figura 1:

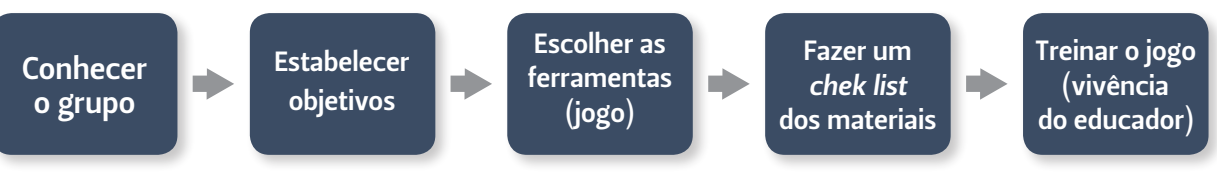

Figura 1 - Planejamento de atividades de Educação Lúdica

Fonte: Desenvolvido pelos autores

Ainda é importante mencionar que o educador que escolhe aplicar a educação lúdica deve, necessariamente, desenvolver em si a capacidade de flexibilizar e adaptar-se a novos contextos. Precisa, assim, estar preparado para lidar com o inesperado, pois cada grupo de alunos é único e reage de forma diferente a cada atividade estabelecida.

Deve-se considerar, então, que um jogo pode despertar sentimentos e emoções - positivas e negativas, e o educador precisa interagir com estas questões, guiando o grupo no processo de construção do conhecimento.

\section{A prática do jogo e seu foco nas competências e habilidades}

Após o planejamento, o docente tem diante de si o desafio de despertar a motivação dos seus alunos, para que voluntariamente se engajem nas atividades lúdicas em sala de aula. Para tanto, precisa conhecer o seu grupo, lançando mão de recursos como conversas iniciais e jogos de entrosamento e conhecimento.

Relevante mencionar que o estabelecimento de um bom entrosamento do grupo é fundamental para que as atividades 
lúdicas sejam realizadas eficazmente. Isso ocorre porque o aluno precisa estar seguro em seu grupo para poder maximizar a sua experiência de aprendizagem lúdica.

As práticas que almejam estabelecer foco, memória e atenção também são interessantes, pois dizem respeito a uma iniciação gradual no cenário lúdico. Por meio de tais práticas os alunos de curso superior têm um melhor rendimento, conseguem assimilar os conteúdos e, principalmente, deixam o cansaço e a preocupação do dia de trabalho longe do ambiente de aula. Nesse cenário é importante ressaltar que:

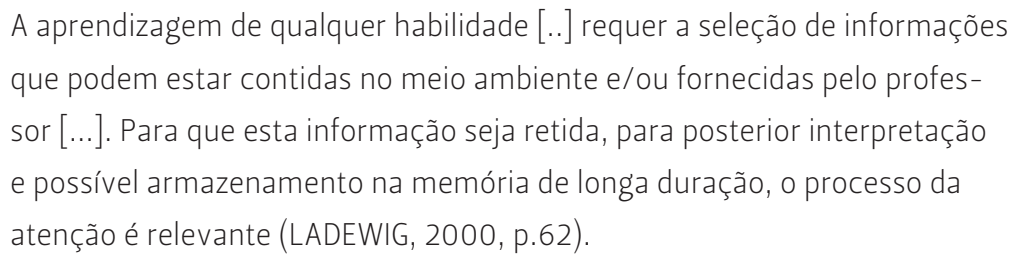

Deve-se considerar, da mesma forma, que ao estabelecer o uso de atividades lúdicas, nota-se que o jogo tem o poder altamente significativo de proporcionar a quem joga um novo cenário, diferente daquele no qual vive concretamente. Assim, trata-se de uma ferramenta muito útil para a aquisição de novos comportamentos, como afirma Soler (2011, p. 28):

\footnotetext{
Por meio do jogo, podemos modificar uma sociedade, tornando-a mais humana, cooperativa e pacífica, ou, ao contrário, tornando essa mesma sociedade extremamente competitiva, violenta e desumana. Embora esta visão possa parecer distante, ela evidencia que a ludicidade pode ser uma aliada na gestão de competências.
}

Dessa forma, pode-se notar que a intenção do jogo pode direcioná-lo a alcançar distintos objetivos. A partir da atividade lúdica transformam-se comportamentos, desenvolvendo competências que poderão ser utilizadas no cenário concreto. A gestão de competências passa então pelo diagnóstico de comportamentos e a ação específica é direcionada para transformá-los. Convém considerar que:

[...] não é uma preocupação exclusiva dos empresários ou dos diretores de recursos humanos. Numa sociedade individualista, todos sabem que são detentores de um capital de competências do qual depende a realização dos seus projetos pessoais, mas também o seu valor no mercado de trabalho e em outros "mercados". Esse capital se desvaloriza se não for mantido e desenvolvido à custa de esforços. (PERRENOUd, 2013, p. 30). 
$\mathrm{Na}$ educação de adultos, busca-se capacitar e possibilitar que as pessoas possam se desenvolver para estarem adaptadas a atuar na sociedade, transformando-a através do uso de suas competências e habilidades. Portanto, a escolha da intenção e direcionamento dos jogos tem, em uma visão positiva, um papel transformador, que pode possibilitar uma alteração na sociedade em ser mais colaborativa.

Deve-se levar em conta que quando se considera jogos, imediatamente pensa-se em "ganhar" e "perder". Em processos iniciais de educação lúdica voltada para adultos no ensino superior, é interessante pensar nessas práticas mais conhecidas, onde há vencedores. Os estudantes, de maneira evidente, têm um espírito competitivo forte, e com uma abordagem que tem mais rivalidade, se sentem mais confortáveis para ingressar na ludicidade.

Contudo, em seguida é oportuno adotar práticas cooperativas - em que todos "ganham" ou "perdem" - quando acontece uma mudança de paradigma e, por consequência, de comportamento. Assim sendo, novas habilidades e competências passam a ser desenvolvidas.

Em um cenário competitivo, cooperar acaba sendo uma ação pouco comum. Isso chama a atenção, uma vez que as pessoas são seres sociais, que se organizam em grupo, sendo essa ação algo que deveria ser natural, como se vê na afirmação de Soler (2011, p. 17):
A primeira coisa que temos que entender é que a cooperação é uma
arte que seduz, emociona e humaniza e, como tal, precisamos, se quisermos saber como aprender a cooperar, seguir alguns passos necessários para se aprender qualquer tipo de arte que nos leve ao encontro de nossos objetivos.

Outro ponto que é atinente aos jogos ou dinâmicas é relativo à sua implementação pelo educador a fim de atingir os objetivos propostos. Militão e Militão (2000) cita que o jogo tem seu início a partir da organização dos participantes, que recebem as instruções preliminares da atividade lúdica. 0 autor aponta que um cuidado especial deve ser tomado ao explanar as regras restritivas, deixando para o grupo implementar as ações ou não ações. A seguir, se for necessário, pode ser gerado algum tipo de demonstração.

Em seguida, aponta Militão e Militão (2000), chega-se ao momento do jogo propriamente dito, no qual o grupo de jogadores 
passará pela vivência e observação, estabelecendo-se o ritmo da atividade. Após a um período de pausa, ou no final do jogo, segue uma conversa sobre sentimentos e emoções estabelecidas durante a atividade.

Deve-se reservar também um tempo para discussões, esclarecimentos e opiniões dos alunos, ocasião na qual a significação da vivência para o aprendizado normalmente acontece. Por fim, é necessário que o educador faça um encerramento da atividade, sendo um ponto importante para fazer ligações com o conteúdo e os conhecimentos prévios, a partir da ancoragem (MILITÃO; MILITÃO, 2000).

A figura 2 abarca os aspectos que são comuns aos jogos e dinâmicas utilizados na educação lúdica:

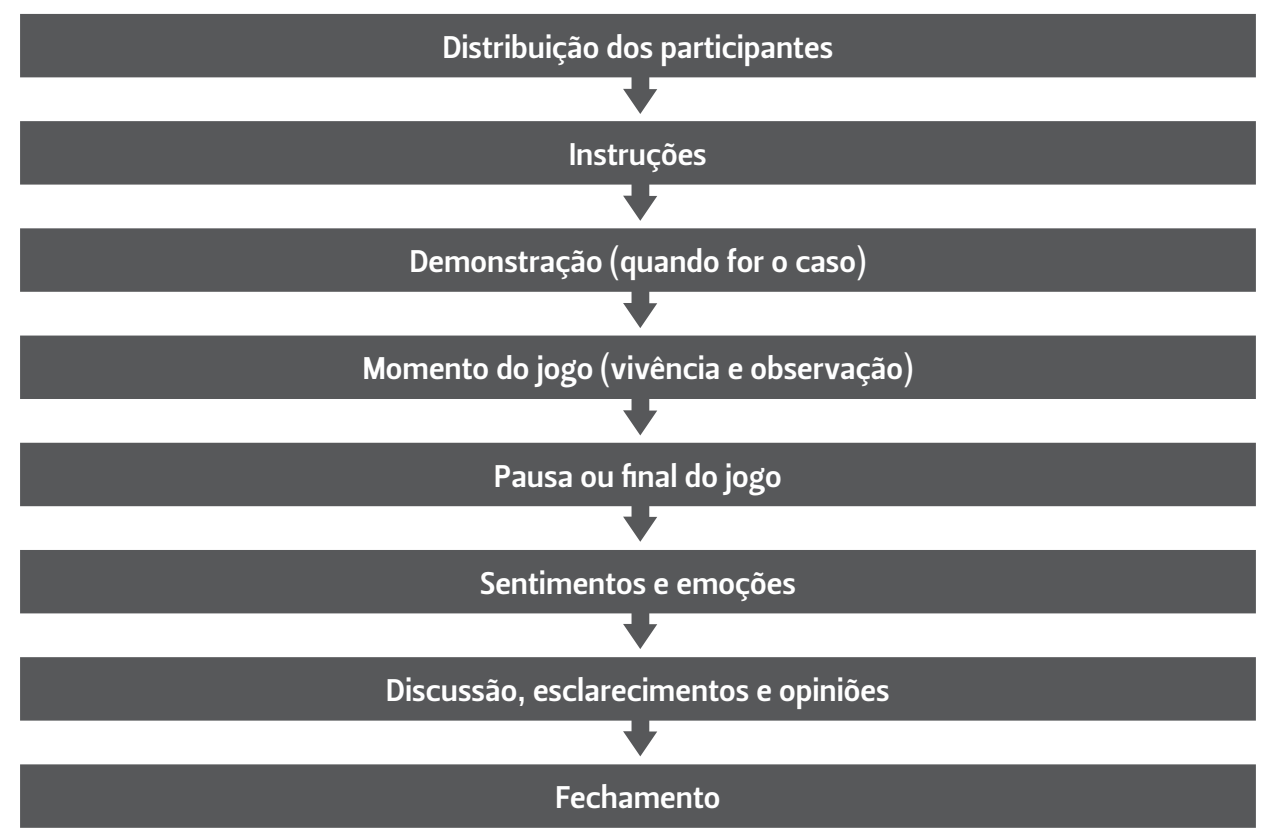

Figura 2 - Fases do Jogo

Fonte: Adaptado de Militão e Militão (2000, p. 29)

Legitimando a esquematização acima, Batllori (2009) indica que em cada jogo deve-se prestar atenção para que exista o material necessário, não se desconsiderando a hipótese de que os próprios alunos desenvolvam o seu material. Ainda, o autor salienta que uma atenção deve ser dada ao grau de dificuldade do jogo baseado nas competências e habilidades prévias de cada jogador identificadas na fase de planejamento.

Outro aspecto importante destacado pelo autor são os objetivos, que podem envolver fatores cognitivos, sociais ou emocionais. 
Além disso, destaque é dado ao desenvolvimento do jogo, importante para o pleno alcance dos seus objetivos. Finalmente, Batllori (2009) destaca a necessidade de solução ou fechamento do jogo.

\section{A finalização da atividade lúdica: importância da significação}

Encerrar uma atividade adequadamente é tão importante quanto à escolha dos assuntos que ela aborda. De acordo com o objetivo, este pode ser o ponto alto da atividade realizada. Este é o período de provocar novos significados para a tarefa proposta, pensar sobre o propósito e finalizar ressaltando os resultados obtidos.

Tal procedimento é de extrema saliência, uma vez que traz à luz o processo de aprendizagem e de metacognição. Segundo Relvas (2010, p. 25).

\footnotetext{
Todo o processo de formação implica em alguma aprendizagem, indicando simplesmente que alguém veio saber algo que não sabia, como uma informação, um conceito, uma habilidade, capacidade. Mas implica que esse "algo novo" que se aprendeu transformou esse alguém.
}

Assim, ao finalizar uma atividade lúdica, o docente deve reger os seus alunos na construção do conhecimento, significando a aprendizagem. Ou seja, o aluno precisa suscitar pontos entre o seu conhecimento anterior e as novas informações e vivências que acaba de adquirir.

Pondera-se, da mesma forma, que a pessoa ao vivenciar uma atividade lúdica de forma genuína foca-se de modo pleno na sua performance, como aponta Luckesi (2005, p. 43):

Enquanto estamos participando verdadeiramente de uma atividade lúdica, não há lugar, na nossa experiência, para qualquer outra coisa além dessa própria atividade. Não há divisão. Estamos inteiros, plenos, flexíveis, alegres, saudáveis. Poderá ocorrer, evidentemente, de estar no meio de uma atividade lúdica e, ao mesmo tempo, estarmos divididos com outra coisa, mas aí, com certeza, não estaremos verdadeiramente participando dessa atividade. Estaremos com o corpo ali presente, mas com a mente em outro lugar e, então, nossa atividade não será plena e, por isso mesmo, não será lúdica. 
Diante disso, considera-se que ao se concluir um jogo com foco no aprendizado é necessário estabelecer a ligação entre os conhecimentos prévios e os conhecimentos adquiridos, ancorando-os. Esse é o ponto de maior significação para se compreender de forma plena a relação entre a teoria e a prática.

Ainda, é preciso levar em conta que, ao apreender e ensinar, um indivíduo interage com os outros, majorando as suas probabilidades de conhecimento. Nesse sentido, Relvas (2009), comenta que "Piaget admite que a espécie humana traz no seu genoma algumas 'possibilidades', mas argumenta, também, que outras possibilidades só se efetivarão mediante as interações" (RELVAS, 2009, p. 115).

Pela mesma via, Luckesi (2005) atenta para as mudanças ocorridas na educação no século XXI, destacando que a principal delas é a necessidade de Aprender a Ser. Trata-se do eixo relevante, segundo o autor, dos quatro pilares para a educação, expostos por Jaques Delors na UNESCO em relatório intitulado Educação: um tesouro a descobrir, Relatório para a UNESCO da Comissão Internacional sobre educação para o Século XXI, em 1999. Continuando, Luckesi (2005, p. 38) afirma que:

\footnotetext{
[...] do ponto de vista filosófico e pedagógico, quatro pilares para educação no século que, brevemente, se iniciará, que são: aprender a conhecer, aprender a fazer, aprender a viver juntos e aprender a ser, colocando este último como "via essencial" para os outros três.
}

Legitimando essa ideia, Relvas (2009) aponta que a interação mútua entre o meio e o organismo proporciona ao ser humano um poder de transformação, que permitem o desenvolvimento das pessoas. Assim, afirma:

\footnotetext{
Uma importante ideia defendida por Vygotsky refere-se à relação entre indivíduo e sociedade. Ele afirma que as características tipicamente humanas (funções psicológicas superiores) não estão presentes desde o nascimento da pessoa, isto é, não são transmitidas por hereditariedade nem são adquiridas passivamente graças às pressões do ambiente externo. São, outrossim, resultado da interação entre indivíduo e meio sócio cultural. Ele chama a atenção para a ação recíproca existente entre o organismo e o meio. Argumenta, também, que o homem, ao mesmo tempo em que atua na natureza transformando-a, sofre os efeitos dessas mudanças que ele mesmo promove (RELVAS, 2009, p. 118).
} 
Ainda, deve-se considerar que ao finalizar uma atividade estabelece-se uma conexão ou correlação com a vida real. Segundo Militão e Militão (2000, p. 21), nesse momento,

\begin{abstract}
Se fazem as comparações dos sentidos teóricos com situações práticas de trabalho e de vida real. As conclusões e aprendizagens elaboradas podem servir para uso imediato ou para o futuro, possibilitando aos participantes "insights" de novas aprendizagens, além de incitá-los à criatividade, à mudança, inovação de procedimentos e novas formas de conduta.
\end{abstract}

A figura 3 apresenta o Processo ou Ciclo Vivencial da Aprendizagem, explicitando que a partir de uma experiência, a pessoa evolve-se em uma metacognição, realizando a ligação entre teoria e prática, tão apregoada na educação de adultos.

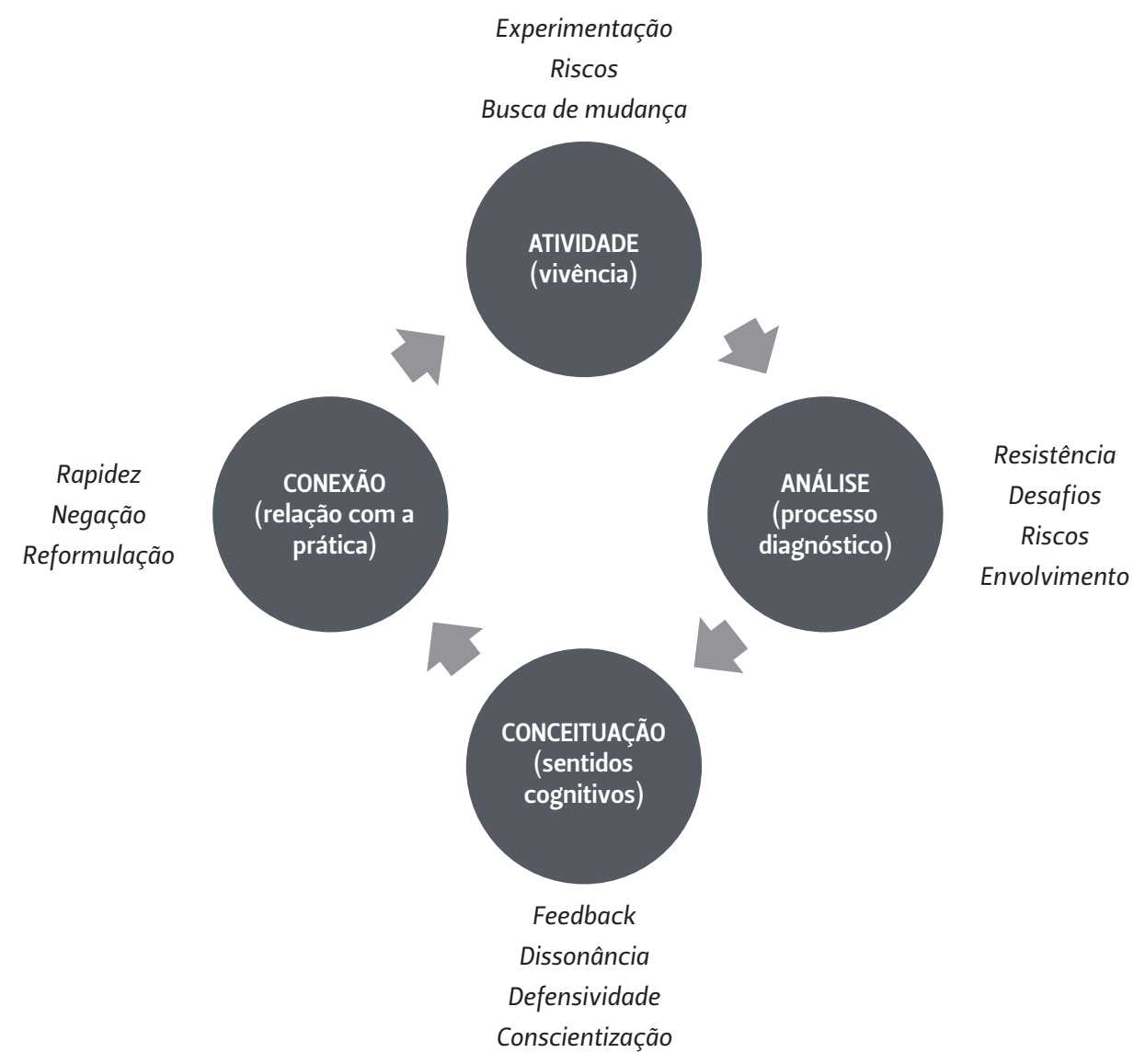

Figura 3 - Processo ou Ciclo Vivencial da Aprendizagem

Fonte: Adaptado de Militão e Militão (2000, p.21)

Diante desse contexto, evidencia-se a necessidade de um ciclo completo de vivência do jogo, encarado em seu cerne educador e gerador de aprendizagens e conhecimentos. Para que isso ocorra, todos os sujeitos nela envolvidos - educadores e alunos - 
precisam estar plenos na atividade para que seus objetivos sejam de fato alcançados.

\section{Considerações finais}

Pode-se afirmar que o principal resultado esperado com o uso de práticas pedagógicas lúdicas é a geração de um conhecimento duradouro, contextualizado e principalmente obtido por meio de experiências prazerosas e emocionalmente positivas, que gerarão significado ao processo da aprendizagem.

Com base nisso, Soler (2011) aponta que os objetivos educacionais, bem como as derivadas competências neles implícitas, podem ser alcançados com prazer, diversão e ludicidade. Para tanto, o autor afirma que é relevante suplantar os regulamentos, estratégias e métodos que normalmente são atinentes a um jogo. Isto porque a compreensão tem um papel significativo na geração de competências, pois "não basta jogar, tem que se entender o que se acabou de fazer. 0 que na verdade se diferencia o racional do irracional é justamente o poder de simbolizar". (SOLER, 2011, p. 28).

Diante do fato de a interação ser um pilar relevante no processo de aprender e ensinar, evidencia-se que com a ludicidade é possível a construção de interações que geram conhecimento. Portanto, é lógico pensar nas formas com que a educação lúdica pode contribuir no desenvolvimento humano.

Nesse sentido, Almeida (2003) menciona a intervenção do docente e a necessidade de alterações na sua forma de atuação - em contraponto ao modelo formal de educação. 0 autor sugere que a atuação do docente na busca de geração de significação esteja aliada ao prazer e a satisfação em aprender e ensinar.

Mas, cabe ressaltar, que tal ideia já vem sendo discutida por educadores há bastante tempo. Assim, Chateau (1987, p. 133) já afirmava:

\footnotetext{
A escola deve se apoiar no jogo, tomar o comportamento lúdico como modelo para confirmar o comportamento escolar. Mas é preciso separar o jogo do trabalho. Por mais estreitas que sejam as relações entre o jogo e o trabalho, há entre si dois comportamentos diferentes.
}

Diante disso, é notório que as mudanças oriundas da educação lúdica proporcionam inúmeras possibilidades que são positivas 
para a melhoria do desempenho acadêmico dos discentes. Além disso, têm impactos visíveis em sua motivação com as aulas, o que representa um avanço qualitativo, significativo em sua formação e desenvolvimento de suas competências e habilidades.

Por isso, a educação lúdica traduz-se como uma alternativa de grande valor, em um momento no qual se discutem conceitos fundamentais na educação, motivados pelo interesse sobre as novas formas de aprender e ensinar. Nesse cenário, o jogo ou o lúdico desempenham um papel relevante e desafiador, que colocam o educando em confronto com situações que podem motivá-lo a desenvolver de forma mais plena suas capacidades.

\section{REFERÊNCIAS}

ALMEIDA, Paulo Nunes. Educação lúdica: técnicas e jogos pedagógicos. São Paulo: Loyola, 2003.

BATLLORI, J. Jogos para treinar o cérebro: desenvolvimento de habilidades cognitivas e sociais. 11. ed., São Paulo: Madras, 2009.

CHATEAU, J. A criança e o jogo. 4. ed. São Paulo: Summus Editorial, 1987.

GHELLI, Guilherme Marcos. A Construção do saber no ensino superior. Cadernos FUCAMP, v. 3, n. 3, 2004. Disponível em: <http://www.fucamp.edu.br/wp-content/ uploads $/ 2010 / 10 / 5-A$-constru $\% 23$ U00c3\%23U00a7\%23U 00c3\%23U00a3o-do-saber-Guilherme.pdf>. Acesso em: 15 set. 2014.

HUIZINGA, J. Homo Ludens: o jogo como elemento da cultura. 4. ed. Tradução: João Paulo Monteiro. São Paulo: Perspectiva, 1993.

LADEWIG, Iverson. A importância da atenção na aprendizagem de habilidades motoras. Rev. Paul. Educ. Fís. São Paulo, supl.3, p.62-71, 2000. Disponível em: <http:// citrus.uspnet.usp.br/eef/uploads/arquivo/v14\%20supl3\%20 artig07.pdf>. Acesso em: 05 jul. 2014.

LUCKESI, Cipriano. Educação, ludicidade e prevenção das neuroses futuras: uma proposta pedagógica a partir da Biossíntese. Disponível em: <http://www.luckesi.com.br/ artigoseducacaoludicidade.htm> Acesso em: 04 jul. 2014. 
MILITÃO, Albigenor; MILITÃO, Rose. Jogos, dinâmicas e vivências grupais. Rio de Janeiro: Qualimark, 2000.

NEUMANN, Jonh von; MORGENSTERN, Oskar. Theory of Games and Economical Behavior. Pricenton: Pricenton University Press, 1944.

PERRENOUD, Philippe. Desenvolver competências ou ensinar saberes? A escola que prepara para a vida. Porto Alegre: Penso, 2013.

QUADROS, Ana Luiza de; MORTIMER, Eduardo Fleury. Fatores que tornam o professor de Ensino Superior bem-sucedido: analisando um caso. Ciênc. educ. (Bauru), Bauru, v.20, n.1, mar. 2014. Disponível em: <http://www.scielo.br/scielo. php? script $=$ sci_arttext $\&$ pid $=$ S1516 $-73132014000100016 \& \operatorname{lng}$ =pt\&nrm=iso>. Acesso em: 20 maio 2014.

RELVAS, Marta Pires. Fundamentos biológicos da educação: despertando inteligências e afetividade no processo de aprendizagem. 4. ed. Rio de Janeiro: Wak, 2009.

RELVAS, Marta Pires. Neurociências e Educação. Rio de Janeiro: Wak, 2010.

SALEN, K.; ZIMMERMANN, E. Regras do jogo: fundamentos do design de jogos. São Paulo: Blucher, 2012.

SEBASTIÃO, Maria Aparecida. Didática do Ensino Superior. Franca: Faculdade Internacional Signorelli, 2014.

SILVA, Jefferson Olivatto da. Ações inclusivas no ensino superior brasileiro. Rev. Bras. Estud. Pedagog., Brasília, v.95, n.240, ago. 2014. Disponível em: <http://www.scielo.br/scielo. php?script=sci_arttext \&pid=S2176-66812014000200009\&lng= pt\&nrm=iso>. Acesso em: 20 set. 2014.

SOLER, Reinaldo. Brincando e aprendendo com os jogos cooperativos. 3. ed. Rio de Janeiro: Sprint, 2011.

Recebido em: 25/07/2014

Revisto em: 23/09/2014

Aprovado em: 26/09/2014

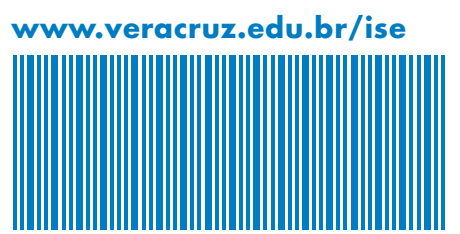

